\title{
Klinefelter Syndrome: A Small Sample Retrospective Analysis
}

Ana Margarida Balsa1, Margarida Bastos², Carolina Moreno², Daniela Guelho², Luís Miguel Cardoso ${ }^{2}$, Nuno Vicente ${ }^{2}$, Diana Martins ${ }^{2}$, Diana Oliveira ${ }^{2}$, Márcia Alves ${ }^{1}$, Joana Guimarães ${ }^{1}$, Francisco Carrilho ${ }^{2}$

1-Serviço de Endocrinologia, Diabetes e Nutrição do Centro Hospitalar do Baixo Vouga, 2-Serviço de Endocrinologia, Diabetes e Metabolismo do Centro Hospitalar e Universitário de Coimbra

\section{Introduction}

Klinefelter Syndrome (KS) is characterized by the presence of supernumerary X-chromosome and thus a 47, XXY karyotype. Although it's the most common numerical chromosomal disorder in males $(150 / 100.000)^{1}$ this syndrome remains underdiagnosed, with only about $25 \%$ of patients being identified, and only $10 \%$ during childhood.

\section{Methods}

Retrospective analysis of $11 \mathrm{KS}$ patients followed-up in the Endocrinology Department of Coimbra's Hospital and Universitary Center. The registered data included education and occupation, time and motif of diagnosis, co-morbidities and treatment. Patients were divided in two groups: A diagnosis at pediatric age, $\mathrm{n}=8 ; \mathrm{B}-$ diagnosis in adulthood, $\mathrm{n}=3$.

\section{Resultados}

11 patients were evaluated, with a mean age of $34,45 \pm 14,2$ years, a mean age of diagnosis of $19,7 \pm 16,5$ years and a mean education of 7,14 years $(n=7)$.

- $\mathbf{N}=\mathbf{8}$
- Mean age of diagnosis : $10,5 \pm 3,1$ years
- Diagnosis in the context of:
-Learning difficulties $(n=8)$
- Puberty induction therapy $(n=8)$
- Mean final stature: $170,3 \pm 9,8 \mathrm{~cm}$
On the last appointment:
Mean age: 24,5 years
- Gynecomastia - 5 patients $(62,5 \%)$
- Osteopenia - 2 patients $(25 \%)$
- No documented changes in carbohydrate
metabolism
- Cognitive deficit - 8 patients $(100 \%)$
- 4 patients finished highschool, 2 with primary
education. 1 illeterate patient $(n=7)$.

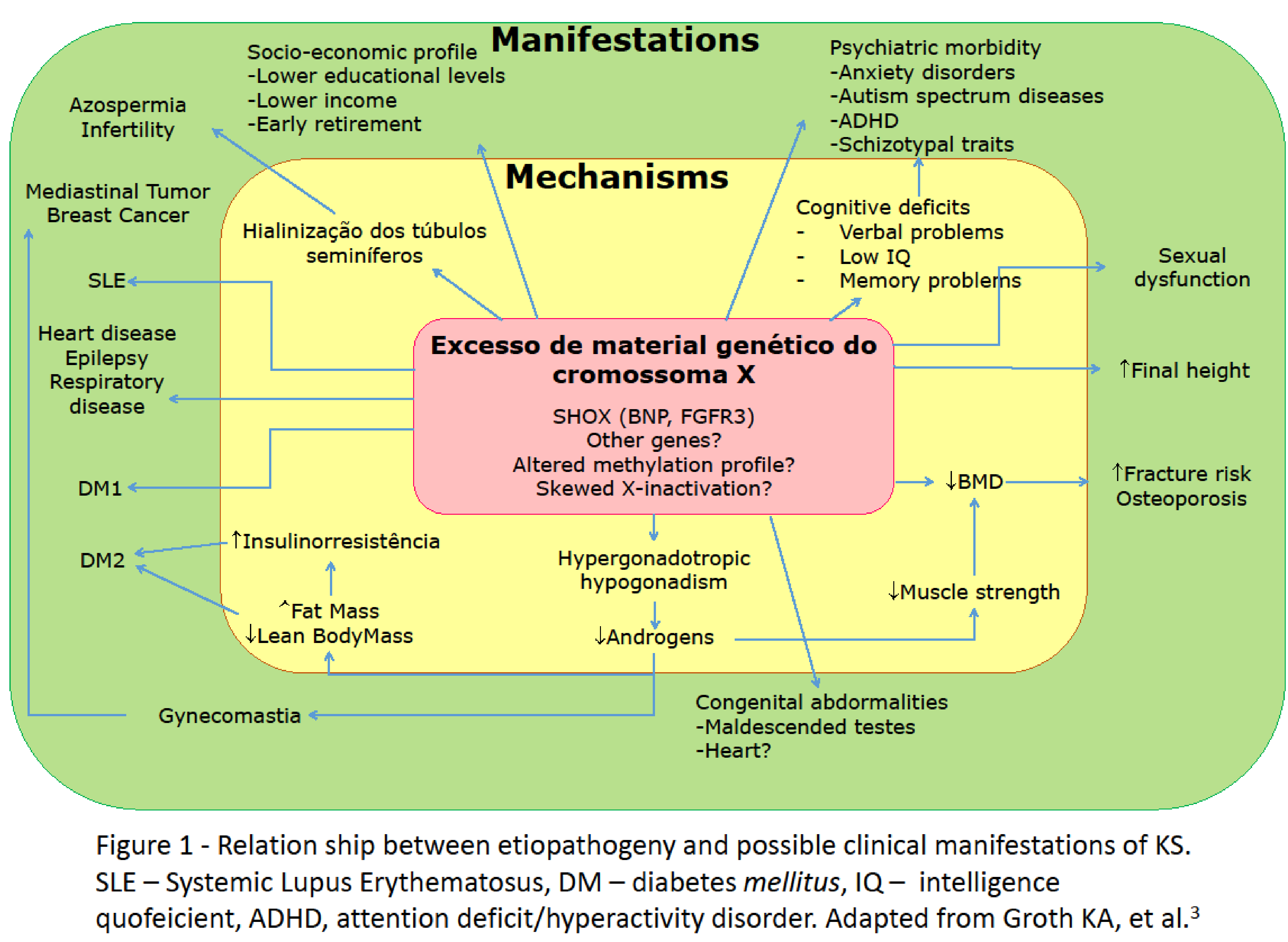

Group B - Diagnosis in adulthood
- N = 3
- Mean age of diagnosis: $42,7 \pm 14,2$ years
- Diagnosis in the context of:
-Study of fertility $(n=1)$
$\quad$-Hypogonadism hypogonadotropic workup
$\quad(n=2)$
- Mean final stature: $177,3 \pm 3,8 \mathrm{~cm}$
On the last appointment:
Mean age: 47 years
- Gynecomastia - 2 patients $(66,7 \%)$
- Osteopenia - 2 patients $(66,7 \%)$
- Osteoporosis - 1 patient $(33,3 \%)$
- DM2 - 2 patients ( $66,7 \%)-$ both with difficult
metabolic control, proliferative retinopathy
- Psychiatric disorders- 2 patients $(66,7 \%)$
- Cognitive deficit- 2 doentes $(66,7 \%)$
- 1 patient finished highschool, now employed. 2
didn't finish primary education, unemployed.

\section{Conclusion}

Cognitive impairment was found in $90,9 \%$ of patients and was the most frequent comorbidity, with educational and professional impact. Gynecomastia and osteopenia were frequent as well. Timely diagnosis can result in a better care with proper follow-up and regular screening of possible comorbidities. 